\title{
Coco peat - An alternative artificial soil ingredient for the earthworm toxicity testing
}

\author{
R. Shanmugasundaram ${ }^{1 *}$, T. Jeyalakshmi ${ }^{1}$, Sweatha S. Mohan ${ }^{1}$, M. Saravanan ${ }^{1}$, A. \\ Goparaju ${ }^{2}$ and P. Balakrishna Murthy ${ }^{3}$
}
${ }^{1}$ Department of Ecotoxicology, International Institute of Biotechnology and Toxicology (IIBAT) Padappai - 601 301, Kancheepuram District, Tamil Nadu, India.
${ }^{2}$ Department of Statistics, International Institute of Biotechnology and Toxicology (IIBAT) Padappai - 601 301, Kancheepuram District, Tamil Nadu, India.
${ }^{3}$ Director of the Institution International Institute of Biotechnology and Toxicology (IIBAT) Padappai - 601301 , Kancheepuram District, Tamil Nadu, India.

\begin{abstract}
The artificial soil medium recommended for invertebrate toxicity studies by OECD and ISO contains sphagnum peat as an organic component. Sphagnum peat is not widely available in tropical countries especially in the Indian subcontinent. Using of native organic matter source is also much more ecologically relevant for the region. Hence, development of an alternative is needed as a replacement of sphagnum peat. As coco peat is easily available as an organic component in tropical countries, earthworm toxicity studies were conducted with coco peat to assess its suitability to be included as an alternative in the artificial soil medium. Artificial soils were prepared with $70 \%$ sand, $20 \%$ kaolin clay and $10 \%$ coco peat (COPS) or sphagnum peat (SPPS). Acute and reproduction toxicity studies were conducted with the earthworm, Eisenia fetida using 2-chloroacetamide and carbendazim, respectively. Validity criteria specified by the guidelines were met in tests with either soil media. In the acute test, no significant difference was observed between the soils in terms of mortality $(p>0.05)$ based on the $L_{50}$ values for COPS and SPPS of 35.56 and $32.36 \mathrm{mg}$ 2-chloroacetamide $/ \mathrm{kg}$ dry soil, respectively. Significant effect in terms of reproduction was observed at $2.06 \mathrm{mg}$ carbendazim/ $/ \mathrm{kg}$ dry soil for both COPS and SPPS. The other parameters such as biomass change, mortality and food consumption were comparable.
\end{abstract}

Key words: Coco peat, shagnum peat, artificial soil, earthworm toxicity, carbendazim, 2-chloroacetamide.

\section{INTRODUCTION}

In terrestrial ecotoxicity assessment, especially with soil living organisms like earthworms, enchytraeids, and collembolans, the toxicity of a substance is strongly influenced by the medium (that is soil type and properties) in which the organisms are exposed. Hence, risk assessment for chemicals in soil has to take into account soil properties. This consideration led to the conclusion that it would be preferable to standardize the soils used for determining the toxicity of chemicals to soil organisms (P Mangala et al., 2009; Gawlik, 2001). In the artificial soil (suggested by the guidelines OECD, 1984; 2004; ISO 2012a;b), sphagnum peat is a component that represent soil organic matter. Among soil ingredients, peat consisted about 5 to $10 \%$ of the total formulation. The other soil ingredients are $69-74 \%$ sand, $20 \%$ clay and 0 to $1 \% \mathrm{CaCO} 3$ (to increase the $\mathrm{pH}$ up to 6.5 ). 
Sphagnum peat is obtained from various species of the plant Sphagnum. Decayed, compacted Sphagnum moss also known as peat or peat moss is used as a soil conditioner. The cost of sphagnum peat is however increasing (Meerow, 1994) and there is a growing concern that it is mined from the endangered Sphagnum plant ecosystems which are declining rapidly due to environmental constraints (Barkham, 1993; Robertson, 1993; Frolking et al., 2001). However, recently, it has become evident that sphagnum peat is scarce and completely unavailable in many regions, including the tropics (P Mangala et al., 2009). Garcia (2011) and Römbke et al. (2007) also considered this problem and suggested using locally available materials like coir dust, for performing soil ecotoxicity tests especially in these regions. Increasing peat-land conservation has also created a need to find possible alternatives. Coco peat also known as coir pith, coir fiber pith, coir dust, or simply coir, is made from coconut husks, a byproducts of industries that use coconuts. Consequently, coco peat is readily available in tropical countries.

Only few studies have been conducted with various organic materials including coco peat as a replacement to sphagnum peat in artificial soil (Noguera et al., 2000; Meerow, 1994; Abbiramy et al., 2012). However, acute and chronic earthworm studies with the chemicals suggested by OECD and ISO guideline are essential to validate the alternate soil so as to be included in the present OECD guideline.

The main objective of the study was to determine the suitability of composed coco peat as an alternative to sphagnum peat in the artificial soil used for earthworm toxicity studies. The soils used in the present studies are referred to as coco peat soil (COPS) and sphagnum peat soil (SPPS). The validation of the COPS was tested in comparison with SPPS using the standard chemicals, such as 2-Chloroacetamide and Carbendazim suggested by OECD guidelines for acute and chronic exposure of earthworms respectively. Comparison of the physicochemical parameters of the two peat samples was also studied.

\section{MATERIALS AND METHODS}

\section{Physico chemical parameter of peat samples}

Before the soil preparation, the physico chemical parameters of the peat types were assessed using the following methods:

1. Water Holding Capacity- As per the Guideline ISO 11268-2 (with slight modification). Since the peat samples in the glass tube floated to the water surface, they were tied in a muslin cloth and immersed in water by keeping weights on the samples.

2. Bulk Density - CIPAC MT-187

3. $\mathrm{pH}$ - CIPAC MT-75

4. Organic Carbon- Jackson (1973)

5. Total organic matters- Jackson (1973)

6. Nitrogen- Van soest (1975)

7. Phosphorus, Calcium, Magnesium- Sundaram et al. (2001)

8. Potassium- JAOAC 39,419 (1956).

\section{Preparation of artificial soils}

The modified artificial soils were prepared as described in the OECD guideline (1984) for sphagnum and composted coco peat, separately. Sphagnum peat imported from Gramoflor $\mathrm{GmbH} \& \mathrm{Co}$ Germany as solid blocks, was shade dried and powdered by grinding machine with a particle size of $<2 \mathrm{~mm}$ using sieves. Similarly, the composted coco peat obtained from Varsha enterprises, Bangalore, India, was also shade dried and pulverised with the same particle size of $<2 \mathrm{~mm}$. The other soil ingredient, kaolin clay was purchased from Romac India Itd, Chennai, India. River sand was used in place of quartz sand with a particle size of approximately 50 to 200 microns. The artificial soil was prepared by mixing $70 \%$ sand, $20 \%$ clay and $10 \%$ peat in as dried constituents in a laboratory homogeniser for $20 \mathrm{~min}$ and stored in an air tight plastic container at room temperature for the coco and sphagnum peat samples separately. As the $\mathrm{pH}$ of both artificial soils were determined to exceed the range specified by the OECD guidelines $(6 \pm 0.5), \mathrm{CaCo}_{3}$ was not needed to increase the $\mathrm{pH}$.

Similarly, for reproduction test, the artificial soil was prepared with the ratio of $69 \%$ sand, $20 \%$ clay, and $10 \%$ peats. Remaining $1 \%$ of sand was added along with test substance since the test item, Carbendazim (98\% pure) was insoluble in any of the solvent. $\mathrm{pH}$ of the artificial soil samples with cow manure powder (at $1 \%$ total weight) was checked and found that these exceeded the range specified by the guideline (ISO, 1994) $(6 \pm 0.5)$. For both the peat based soils, $\mathrm{CaCO}_{3}$ was not needed to increase the $\mathrm{pH}$.

The Maximum Water Holding Capacity (MWHC) of each soil samples were done by the method specified in the guideline (OECD, 2004) with slight modifications. Approximately, $50 \%$ of the MWHC was used to moisten the soil for the earthworm survival in the soils for both acute and chronic tests.

\section{Evaluation of earthworm toxicity}

Toxicity studies included both acute and chronic using the test chemicals suggested by OECD and ISO guidelines. The validation of the soils were done via acute and reproduction (chronic) toxicity tests to the earthworm, Eisenia fetida, obtained from the culture maintained in the Department of Ecotoxicology, International Institute of Biotechnology and Toxicology (IIBAT). The test chemical suggested by the guidelines (OECD, 1984; ISO, 1993), namely, 2Chloroacetamide (100\% pure, Sigma Aldrich, Netherlands) and Carbendazim (>97\% pure, Sigma Aldrich, Netherlands) as suggested by the guideline were used to validate the soils for acute and chronic tests, respectively.

\section{Acute toxicity test}

Glass beakers of $1 \mathrm{~L}$ capacity with a cross sectional areas of 113 $\mathrm{cm}^{2}$ were used in the experiments. For each replicates, about $550 \pm 10 \mathrm{~g}$ of dry artificial soil was filled into the beaker. The dried artificial soil was moistened to approximately half of the final water content one day before the application to avoid the dust emission during test compound application. Five treatment of 2Chloroacetamide: 24, 30, 38, 47 and $59 \mathrm{mg} / \mathrm{kg}$ dry soil and an untreated control (moistened with deionised water) were prepared separately for each soil type. The concentrations were selected based on a preliminary range finding test. The respective amounts of test chemical were weighed in separate glass vials, dispersed in a determined quantity of deionised water (about $30 \mathrm{ml} / 100 \mathrm{~g}$ dry soil), applied to the artificial soil and homogenised using a laboratory mixer. Healthy earthworms (4 to 6 months old with a wet weight of 350 to $550 \mathrm{mg} /$ worm (with gut content) with welldeveloped clitellum which were acclimated for one day in the respective soils were selected, washed with tap water, blotted 
carefully with filter paper, weighed and released on the surface of the treated artificial soil. Four replicate for each concentrations and control were used, with ten earthworms in each replicate. The test containers were incubated in a temperature controlled room at $20 \pm 2^{\circ} \mathrm{C}$ and 400 to 800 lux continous light on the test containers for 14 days. The $\mathrm{pH}$ of the artificial soil at start of the test was 6.67 and 6.80 for sphagnum peat soil (SPPS) and coco peat soil (COPS), respectively.

After 7 and 14 days of exposure, the artificial soils were removed from the containers and the earthworms were counted as live or dead. Due to rapid decomposition in the soil, the missing earthworms were considered as dead. After the mortality check on day 7 , the live earthworms and the artificial soil were returned to the respective test containers. The total and the mean body weights of all live earthworms in each test container were determined at the test start (day 0) and end (day 14). Based on the weight difference between initial and final weight, the biomass change was calculated. At the end of 14 days, moisture content and $\mathrm{pH}$ of the artificial soils were assessed.

\section{Reproduction (Chronic) toxicity test}

Glass beakers of $2 \mathrm{~L}$ capacity with $150 \mathrm{~cm}^{2}$ cross sectional area were used for reproduction test. For each replicate, about $500 \pm 10 \mathrm{~g}$ of dry artificial soil was filled into the beaker. Pre moistening of artificial soil was done with approximately half of the final water content one day before the application to avoid the dust emission during test compound application. On the day of experiment, the remaining water was added along with test item-quartz sand mixture. Based on a preliminary 14 days acute range finding test results, nine treatment concentrations of Carbebdazim, namely, 0.2, $0.35,0.64,1.14,2.06,3.70,6.67$ and $12.00 \mathrm{mg} / \mathrm{kg}$ dry soil were prepared separately for each soil type and a control (moistened with deionised water). The respective amounts of test chemical were weighed in separate glass vials. Since the test item was not soluble in solvents, it was dispersed in $5 \mathrm{~g}$ of quartz sand for each concentration separately, applied to the artificial soil, and homogenised using a laboratory mixer. Healthy earthworms (4 to 6 months old with a wet weight of 280 to $490 \mathrm{mg} /$ worm including gut contents) with well-developed clitellum were acclimated for one day in the respective soils. During acclimatisation, powdered wet cow manure was added on the top of the soil. Ten earthworms were added to each of the four replicates of treated soil and to each of the eight replicates of control soil. The test containers were incubated at temperature controlled room at $20 \pm 2^{\circ} \mathrm{C}$. The light intensity of 400 to 800 lux with $16: 8 \mathrm{~h}$ light:dark cycle was maintained.

Adult earthworms were exposed to treated soil for 4 weeks. After 4 weeks, adults were sorted from the soil and observed for mortality. The live earthworms were weighed and discarded. The soils of each treatment replicate was then returned to the respective containers and incubated under the same test conditions for additional 4 weeks for reproduction assessment.

After a total of 8 weeks (56 days), the number of juveniles in each container was determined. Juveniles were collected from the soil manually by sorting the soil in enamel tray then the tray was placed in a water bath at approximately $50^{\circ} \mathrm{C}$. Juveniles which wriggle out from the soil were counted. Soil was then sorted again manually to recover the remaining juveniles if any. Soil $\mathrm{pH}$ and soil water content were determined for each treatment group at start and end of the test.

Cow manure from clinically normal cows was collected, shade dried and powdered for use as food for the earthworms. One day after test item application, $12 \mathrm{~g}$ of feed $(5 \mathrm{~g}$ of finely ground cow manure was mixed with $7 \mathrm{~g}$ deionised water) was scattered uniformly on the soil surface in each container. Observation of feed consumption was made visually and based on the previous week consumption; the fresh feed was added in the same way for the first four weeks of the experiment (that is, days 1, 8, 15 and 22). After removal of the adult worms on day 28 , cow manure $(5 \mathrm{~g} /$ container $)$ was carefully mixed into the artificial soil to feed the juveniles. No additional food was given thereafter.

\section{Statistical analysis}

All the statistical analyses were carried out with TOXSTAT version 3.5 software. Statistical tests used for the study are thus:

1. For the acute study, the parameters and the statistical tests used are as follows:

a. LC $_{50}$ - Probit analysis (Finney, 1971)

b. No observed effect concentration (NOEC) based on Biomass Dunnett's test (multiple comparison, one-sided, $(\alpha=0.05)$ )

c. NOEC based on Mortality Fisher's exact test

$(\alpha=0.05)$

d. Comparison toxicity level of soils- Two factorial ANOVA

e. Comparative physico-chemical parameters - Student's t test

2. For the chronic study, the parameters and the statistical tests used are as follows:

a. $\mathrm{LC}_{50}$ and $\mathrm{EC}_{50}$ - Probit analysis (Finney, 1971)

b. NOEC based on Biomass and reproduction-Bonferroni test (multiple comparison, one-sided, $\alpha=0.05$ ) and Wilcoxon's Rank Sum Test

c. NOEC based on Mortality-Fisher's exact test $\quad(\alpha=0.05)$

d. Comparison of soils-Two factorial ANOVA

e. Comparative physico-chemical parameters - Student's t test

\section{RESULTS}

\section{Physico-chemical parameters of peats}

The physico-chemical properties such as pH (CIPAC MT75), total organic carbon and total organic matter (Jackson, 1973), phosphorus, calcium, magnesium (Sundaram et al., 2001), nitrogen (Van soest, 1975), potassium (JAOAC, 1956), water holding capacity and bulk density of composted sphagnum and coco peat are as shown in Table 1. Physico-chemical properties differed significantly between the peat samples. Water holding capacity, organic carbon and total organic matters were significantly higher in sphagnum peat as compared to coco peat. However, the macro nutrients $(\mathrm{N}, \mathrm{P}, \mathrm{K})$ and micro nutrients (Calcium and Magnesium) were significantly higher in coco peat than in sphagnum peat.

\section{Acute effect}

The acute effect of 2-Chloroacetamide on earthworm, $E$. fetida are shown in Table 2. Significant mortality was observed at $30 \mathrm{mg}$ a.i./kg dry soil and greater concentrations, in either COPS or SPPS, compared with their respective controls. Complete mortality was observed in $59 \mathrm{mg}$ a.i. $/ \mathrm{kg}$ dry soil, the highest concentration in both soils tested. The $L C_{50}$ values of 35.56 and $32.36 \mathrm{mg}$ a.i./kg dry soils were determined for COPS and SPPS, 
Table 1. Physico-chemical properties of composted sphagnum and coco peat.

\begin{tabular}{|c|c|c|}
\hline Parameter & Sphagnum peat & Coco peat \\
\hline Water holding capacity (\%) & $\begin{array}{l}540.85 \\
(14.03)\end{array}$ & $\begin{array}{c}481.61^{*} \\
(6.71)\end{array}$ \\
\hline Bulk density $(\mathrm{g} / \mathrm{mL})$ & $\begin{array}{l}0.143 \\
(0.01)\end{array}$ & $\begin{array}{l}0.193^{*} \\
(0.01)\end{array}$ \\
\hline $\mathrm{pH}\left(\right.$ in $\left.0.01 \mathrm{M} \mathrm{CaCl}_{2}\right)$ & $\begin{array}{c}3.62 \\
(0.02)\end{array}$ & $\begin{array}{l}4.74^{*} \\
(0.03)\end{array}$ \\
\hline Organic carbon (\%) & $\begin{array}{l}47.19 \\
(0.76)\end{array}$ & $\begin{array}{l}38.04^{*} \\
(0.42)\end{array}$ \\
\hline Total organic matters (\%) & $\begin{array}{l}98.62 \\
(1.21)\end{array}$ & $\begin{array}{l}89.09^{*} \\
(1.02)\end{array}$ \\
\hline $\mathrm{N}(\mathrm{mg} / \mathrm{kg})$ & $\begin{array}{l}1250 \\
(7.61)\end{array}$ & $\begin{array}{l}1380^{*} \\
(4.55)\end{array}$ \\
\hline $\mathrm{P}(\mathrm{mg} / \mathrm{kg})$ & $\begin{array}{c}125 \\
(1.22)\end{array}$ & $\begin{array}{l}350^{*} \\
(2.79)\end{array}$ \\
\hline $\mathrm{K}(\mathrm{mg} / \mathrm{kg})$ & $\begin{array}{c}5788 \\
(12.58)\end{array}$ & $\begin{array}{c}6490^{*} \\
(15.28)\end{array}$ \\
\hline $\mathrm{Ca}(\mathrm{mg} / \mathrm{kg})$ & $\begin{array}{l}92500 \\
(301.4)\end{array}$ & $\begin{array}{l}97500^{*} \\
(300.0)\end{array}$ \\
\hline $\mathrm{Mg}(\mathrm{mg} / \mathrm{kg})$ & $\begin{array}{r}1500 \\
(4.68) \\
\end{array}$ & $\begin{array}{l}2500^{*} \\
(7.99)\end{array}$ \\
\hline
\end{tabular}

*Significantly different from sphagnum peat ( $t$ test $\alpha=0.05$ ). $P=0.024$. Figures in parentheses are standard deviation.

respectively (With 95\% confidence interval of 34.18 to 37.02 and 30.85 to $33.80 \mathrm{mg}$ a.i. $/ \mathrm{kg}$ dry soil for COPS and SPPS, respectively).

Significant biomass change from control was observed from the concentration, $30 \mathrm{mg}$ a.i./.kg dry soil in both SPSS and COPS. The NOEC related to biomass was observed at $24 \mathrm{mg} 2$-Chloroacetamide $\mathrm{mg} / \mathrm{kg}$ dry soil for both COPS and SPPS. The overall comparisons on biomass change between the soils were not significant (Two-factorial ANOVA, $p>0.05$ ).

\section{Reproduction effect}

The effect of Carbendazim on mortality and biomass change of $E$. fetida is shown in Table 3 . No mortality was observed up to the concentration of $2.06 \mathrm{mg}$ a.i. $/ \mathrm{kg}$ dry soil for both soils tested. Significant mortality was observed from the concentration of $6.67 \mathrm{mg}$ a.i./kg dry soil for both COPS and SPPS. The LC50 of Carbendazim at 28 days after exposure was observed as 6.72 and 6.33 $\mathrm{mg}$ a.i. $/ \mathrm{kg}$ dry soil for COPS and SPPS, respectively (With $95 \%$ confidence interval of 6.06 to 7.38 and 5.85 to $6.80 \mathrm{mg}$ a.i. $/ \mathrm{kg}$ dry soil for COPS and SPPS, respectively). The NOEC and LOEC values related to mortality were found to be 3.70 and $6.67 \mathrm{mg}$ a.i. $/ \mathrm{kg}$ dry soil, respectively for both the soils (Fisher's exact test). The overall comparison at all the dose response level of the soils on mortality was not significant (Two-factorial ANOVA, $p=0.05$ ).

The biomass of adult earthworms exposed for 28 days showed an increase in both the controls of COPS $(+27.26 \%)$ and SPPS (+32.01\%). Significant biomass change from control was observed from the concentration, 2.06 and $3.70 \mathrm{mg}$ a.i./.kg dry soil in COPS and SPPS, respectively. Hence, the NOEC related to biomass was found to be 1.14 and $2.06 \mathrm{mg}$ a.i. $/ \mathrm{kg}$ dry soil for COPS and SPPS, respectively (Dunnett test). The 
Table 2. Acute effect of 2-chloroacetamide on the earthworm, Eisenia fetida in formulated soils using coco peat and sphagnum peat.

\begin{tabular}{|c|c|c|c|c|c|c|c|c|}
\hline \multirow[b]{2}{*}{ Parameter } & \multirow[b]{2}{*}{ Soil type } & \multirow{2}{*}{$\begin{array}{c}\text { Control } \\
\text { (deionised water) }\end{array}$} & \multicolumn{5}{|c|}{ 2-chloroacetamide (mga.i./kg dry soil) } & \multirow{2}{*}{$\begin{array}{c}\text { Statistical } \\
\text { comparison } \\
\text { between soils ( } P \\
\text { value) }\end{array}$} \\
\hline & & & 24 & 30 & 38 & 47 & 59 & \\
\hline \multirow{2}{*}{ Mortality after 14 days (\%) ${ }^{1}$} & COPS & 0 & $0^{\text {n.s }}(-)$ & $25.00^{*}(5.8)$ & $67.50^{*}(9.6)$ & $95.00^{*}(5.8)$ & $100^{*}(-)$ & \multirow{2}{*}{$0.0012^{*}$} \\
\hline & SPPS & 0 & $5.00^{\text {n.s }}(5.8)$ & $40.00^{*}(8.2)$ & $80.00^{*}(14.1)$ & $100^{*}(-)$ & $100^{*}(-)$ & \\
\hline \multirow{2}{*}{ Biomass change after 14 days $(\%)^{2}$} & COPS & $-13.81(4.65)$ & $-19.70(6.5)$ & $-20.09^{*}(12.9)$ & $-50.55^{\star}(5.2)$ & $-78.64^{*}(24.7)$ & $-100^{*}(-)$ & \multirow{2}{*}{$0.2549^{\text {ns }}$} \\
\hline & SPPS & $-12.53(2.38)$ & $-22.41^{*}(3.3)$ & $-29.52^{*}(5.4)$ & $-35.77^{*}(3.5)$ & $-100 *(-)$ & $-100 *(-)$ & \\
\hline
\end{tabular}

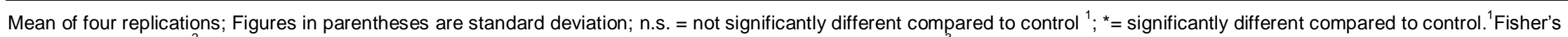
exact test $(\alpha=0.05) ;{ }^{2}$ Dunnett test $(\alpha=0.05)$ for SPPS and Steel's many one rank test $(\alpha=0.05)$ for COPS; ${ }^{3}$ Two-factorial ANOVA.

Table 3. Reproduction effect of Carbendazim on the Earthworm, Eisenia fetida in formulated soils using coco peat and sphagnum peat

\begin{tabular}{|c|c|c|c|c|}
\hline \multirow{2}{*}{$\begin{array}{c}\text { Carbendazim concentrations } \\
\text { (mg a.i/kg dry soil) }\end{array}$} & \multicolumn{2}{|c|}{ Mortality (\%) ${ }^{1}$} & \multicolumn{2}{|c|}{ Biomass change $(\%)^{2}$} \\
\hline & COPS & SPPS & COPS & SPPS \\
\hline Control & 0.0 & 0.0 & $+27.26(5.2)$ & $+32.01(6.4)$ \\
\hline 0.20 & 0.0 & 0.0 & $+29.69^{\text {n.s }}(9.1)$ & $+37.46^{\text {n.s }}(4.2)$ \\
\hline 0.35 & 0.0 & 0.0 & $+30.82^{\text {n.s }}(2.2)$ & $+37.39^{\text {n.s }}(5.1)$ \\
\hline 0.64 & 0.0 & 0.0 & $+31.26^{\text {n.s }}(6.8)$ & $+20.04^{\text {n.s }}(5.5)$ \\
\hline 1.14 & 0.0 & 0.0 & $+31.53^{\text {n.s }}(4.9)$ & $+37.00^{\text {n.s }}(3.0)$ \\
\hline 2.06 & 0.0 & 0.0 & $+11.96^{\star}(1.1)$ & $+23.71^{\mathrm{n} . \mathrm{s}}(10.5)$ \\
\hline 3.70 & $2.50(5.0)$ & $2.50(5.0)$ & $-30.11^{*}(3.1)$ & $-39.76^{*}(5.5)$ \\
\hline 6.67 & $67.50^{*}(9.6)$ & $80.00^{*}(8.2)$ & $-52.51^{*}(4.0)$ & $-60.72^{*}(17.8)$ \\
\hline 12.00 & $95.00 *(10.0)$ & $-100^{*}$ & $-61.76^{*}(3.5)$ & $-100^{*}$ \\
\hline
\end{tabular}

Statistical comparisons between soil ${ }^{3}$

\section{$P$ value}

Mean of four replications; figures in parentheses are standard deviation, n.s $=$ not significantly different; ${ }^{*}=$ significantly different ${ }^{1}$ Fisher's exact test $(\alpha=0.05) ;{ }^{2}$ Bonferroni test $(\alpha=0.05) ;{ }^{3}$ Two-factorial ANOVA.

overall dose response biomass change for both soils were not significant (Two-factorial ANOVA, $\alpha$ $=0.05$ ).

The reduction in reproduction for the concentra- tions of carbendazim over control is shown in Figure 1. The mean number of juveniles produced was found to range from 0 to 92 and 0 to 87.5 in coco peat and sphagnum peat treated soils, respectively (Figure 2). The significant effect on reproduction was observed at $2.06 \mathrm{mg}$ a.i./.kg dry soil for both COPS and SPPS. However, the effective concentration based on reproduction 


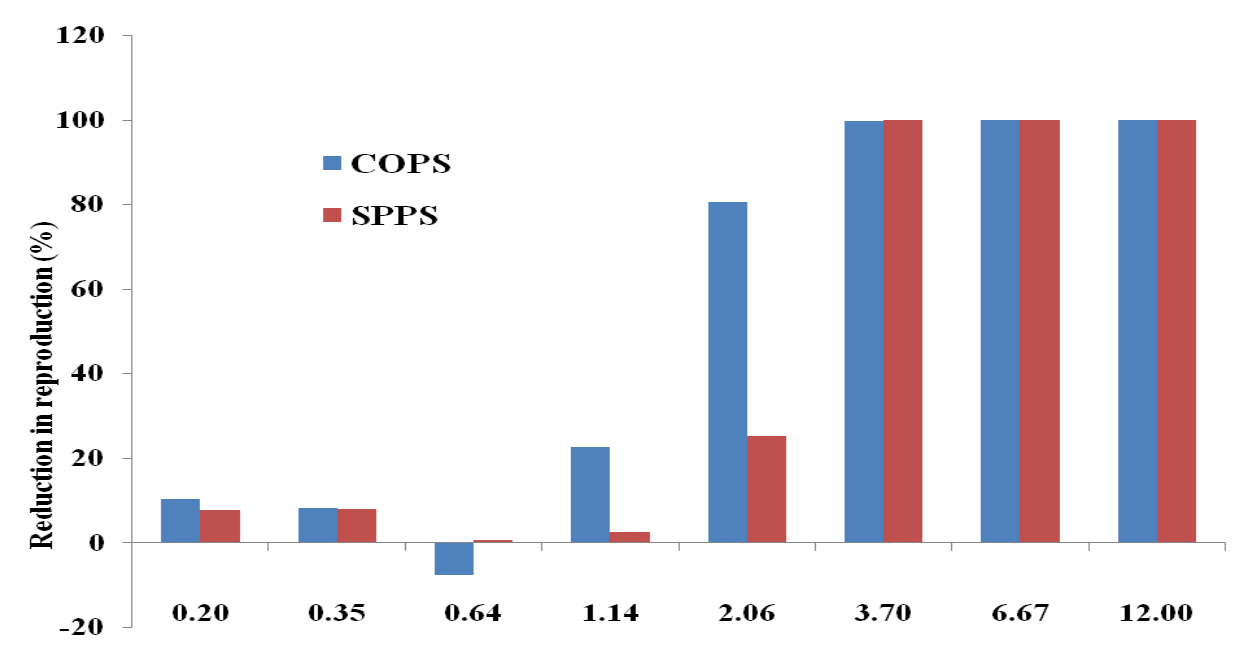

Concentrations (mg/kg dry soil)

Figure 1. Dose response relationship of coco and sphagnum peat soils on reduction in reproduction over control.

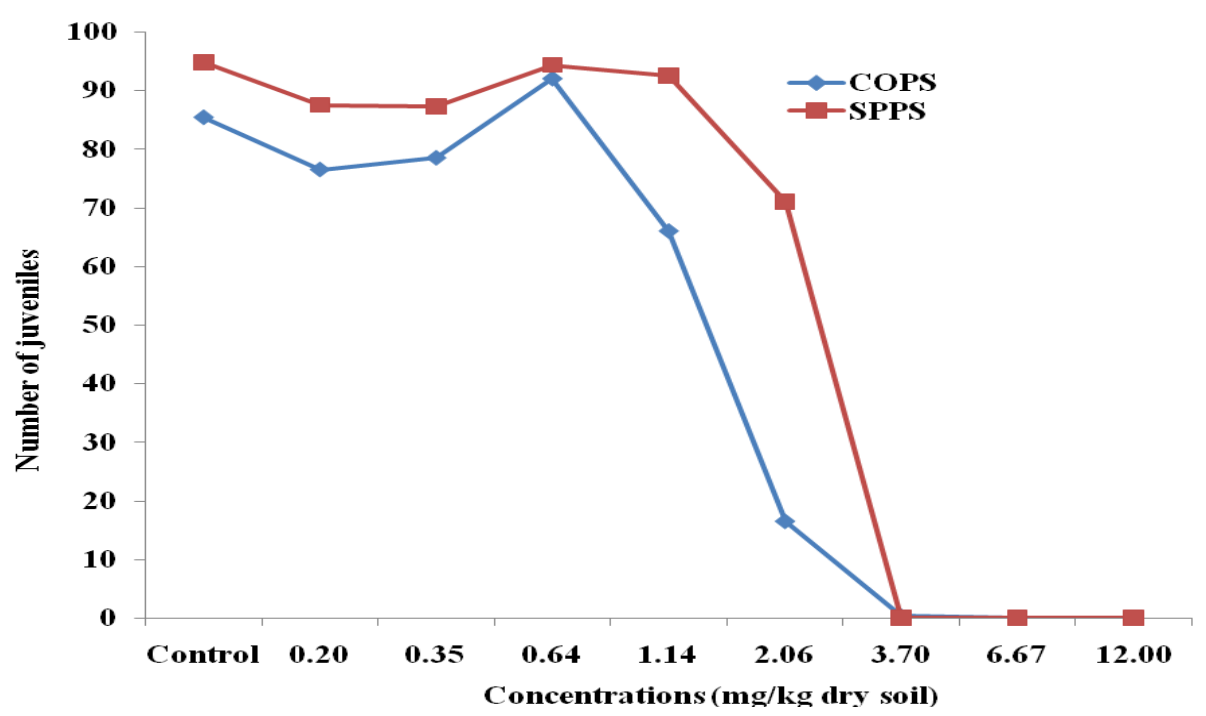

Figure 2. Dose response relationship of coco and sphagnum peat soils on juvenile production.

$\left(E_{50}\right)$ of COPS and SPPS was found to be 1.35 and $2.45 \mathrm{mg}$ a.i./kg dry soil, respectively.

\section{DISCUSSION}

In a toxicity study with earthworm, the nature of the soil medium is a crucial role to decide the toxicity of the xenobiotics on earthworms despite other factors like temperature, light intensity, etc. In the present study, the test medium which was compared under similar experiment conditions were identical in all aspects but for the peat. Hence, the reason for the variable endpoints is attributed to the variation in the soil ingredient, especially the organic content, peat.

Analysis of physico-chemical properties of the biological materials resulted in significant variation. $P$ Mangala et al. (2009) studied similar physico-chemical properties in the prepared artificial soil. The $\mathrm{pH}$ of the sphagnum peat was found to be significantly acetic when compared to coco peat which was in line with reports of Geoff (2011). Though the $\mathrm{pH}$ of the peat samples was found significantly different, there was no significant variation between artificial soil samples. 
Water holding capacity of sphagnum peat was significantly higher than that of coco peat. Similarly, the moisture content of the two soils during the acute and chronic experiment varied from 30.07 to $32.66 \%$ and 32.81 to $37.76 \%$ for COPS and SPPS treated soils, respectively. The moisture content is also influencing toxicity of certain compounds (Puurtinen and Martikainen, 1997). In this study, there was no appreciable variation in moisture content of the two soils, indicating that the moisture content is not influencing toxicity. The total organic matters play an important role to predict biological response of earthworms in $\mathrm{Cu}$ contaminated soil (Gonzalo, 2009). The concentration of essential elements such as NPK, $\mathrm{Mg}$ and $\mathrm{Ca}$ was significantly higher in coco peat than sphagnum peat samples. Manuel Abad et al. (2005) studied significant variation in the physico-chemical properties of coco peat with different locations in which they are growing. The variation of physico-chemical properties with location is not only applicable for coco peat but also for the sphagnum peat. Abbiramy et al. (2012) also observed similar physico-chemical characteristics in the two peat samples. This study is also in line with their findings, except for few properties. They validated the soil with coco peat using urea as substance.

The validity criteria such as control mortality $(\leq 10 \%)$ and mean weight loss in control $(\leq 20 \%)$ for acute earthworm toxicity test were met in both the soils tested (Organisation for Economic Co-operation and Development (OECD), 1984; International Organisation for Standardisation (ISO), 2012). As per the ISO guideline (ISO, 2012), the $\mathrm{LC}_{50}$ of the reference compound, 2chloroacetamide should be 20 to $80 \mathrm{mg}$ a.s $/ \mathrm{kg}$ dry soil. This value is specified to validate the test condition, especially for the exposing medium (artificial soil). The $\mathrm{LC}_{50}$ of 2-chloroacetamide for SPPS and COPS was well within the range specified by the guideline. Hence, both the soil met the validity criteria specified by the guideline. Though the $\mathrm{LC}_{50}$ of 2-chloroacetamide was found to be within the validity range, the comparative analysis on mortality revealed that there was a significant difference between the soils (two-factorial analysis of variance (ANOVA), $p<0.05$ ). This may be due to the variation in the soils properties. However, the difference in the soil properties was not influenced in biomass change. Therefore the 14 days acute test on earthworm with coco peat is comparable with sphagnum peat. Though the soil components differed between soils, mortality of carbendazim between the soils was not significant, which is in line with Sian et al. (2007) who reported that the soil components did not greatly influence carbendazim toxicity to $E$. fetida.

The number of juveniles in control ranged from 70 to 102 in COPS and 72 to 128 in SPPS. Though there was a significant variation in number of juveniles produced between the soils, both of them met the validity criteria specified by the guideline. The coefficient of variation also met the guideline requirement which was observed to be $14.32 \%$ in COPS against SPPS (17.85\%). The $\mathrm{EC}_{50}$ of carbendazim showed that there is no difference between the two soil types tested (1.35 and $2.45 \mathrm{mg}$ a.s $/ \mathrm{kg}$ dry soil for COPS and SPPS, respectively). However the $E_{50}$ value of carbendazim reported by $P$ Mangala et al. (2009) for coco peat and sphagnum peat soil was observed as 1.2 and $1.0 \mathrm{mg}$ a.s/kg dry soil, respectively.

\section{Conclusions}

The following conclusions can be drawn based on the results of the study:

1. Peat material, the only organic ingredient in the artificial soil medium, plays a major role in determination of toxicity level in earthworm toxicity testing. 2. Physicochemical properties of peat material do not significantly influence earthworm toxicity.

3. Composted coco peat is a good organic source for the replacement of sphagnum peat in artificial soil preparations.

4. The alternate artificial soil prepared using coco peat can be used to perform earthworm toxicity studies (both acute and chronic), especially in tropical countries.

\section{ACKNOWLEDGEMENTS}

The authors are thankful to Dr. A. Ramesh, Head, Department of Analytical Chemistry, IIBAT for providing facility to analyse the physico chemical properties of peat samples. The authors also appreciate Mr. R. Radhakrishnan, Scientist, Department of Analytical Chemistry and Ms. S. Hilda, Scientist, Department of Ecotoxicology IIBAT for their useful contribution to fulfill this paper work.

\section{REFERENCES}

Abbiramy KS, Ronald Ross $\mathrm{P}$, Thenmozhi $\mathrm{P}$, Muthulingam $\mathrm{M}$, Paramanandham J, Manoharan V (2012). The validation of modified tropical artificial soil by ecotoxicological studies on Eisenia foetida. Int. J. Dev.Res.2(5):1051-1056.

Alan W Meerow (1994). Coir Dust, A Viable Alternative to Peat Moss. TropicLine 7(3).

Barkham JP (1993). For peat's sake: conservation or exploitation? Biodiversity Conservation. 2:556-566.

Finney DJ (1977). "Probit Analysis", Third Edition, Cambridge University Press London.

Frolking S, Roulet NT, Moore TR, Richard PJH, Lavoie M, Muller SD (2001). Modeling northern peat-land decomposition and peat accumulation. Ecosystems. 4:479-498.

Garcia M, Scheffczyk A, Garcia T, Rombke J (2011). The effects of the insecticide lambda-Cyhalothrin on the earthworm Eisenia fetida under experimental conditions of tropical and temperate regions. Environ. Pollut. 159:398 - 400.

Gawlik BM, Lamberty A, Muntau H Pawels (2001). J. Euro-Soils - A set of CRMs for comparability of soil- measurements. Fresenius J. Anal. Chem. 370(2-3):220-3.

Geoff C (2011). "coir dust a proven alternative to peat" cress well 
horticultural services 119 cabbage tree road grose vale NSW 2753.

Gonzalo A, Hernán G, Sébastien S, Alexander N (2009). Organic Matter Reduces Copper Toxicity for the Earthworm Eisenia fetida in Soils fromMining Areas in Central Chile. Chilean J. Agri. Research 69(2):252-259.

ISO (1994). Soil quality- Determination of pH, ISO 11465: International Organization for Standardization, Geneva, Switzerland.

ISO (2012) Soil quality- Effects of pollutants on earthworms (Eisenia fetida) - Part 1: Determination of acute toxicity using artificial soil substrate" ISO 11268-1. International Organization for Standardization, Geneva, Switzerland.

ISO (2012). Soil quality-effects of pollutants on earthworms (Eisenia fetida) part 2: Determination of effects on reproduction, ISO 11268-2. International Organization for Standardization, Geneva, Switzerland.

Jackson ML (1973). Collaborative International Pesticides Analytical Council (CIPAC) Soil Chemical analysis. Prentice Hall of India Private Limited, New Delhi MT 75.

Jackson ML (1973). Soil Chemical analysis. Prentice Hall of India Private Limited, New Delhi. J. Appl. Organic Anal. Chem. 39:419, 1956.

Manuel A, Fernando F, Carolina C, Vicente N (2005). Physical properties of various coconut coir Dusts compared to peat. Hort. Sci. 40(7):2138-2144.

Meerow AW. (1994). "Growth of two subtropical ornamentals using coir (coconut mesocarp pith) as a peat substitute" Hort. Sci. 29:14841486.

Noguera P, Abad M, Noguera V, Puchades R, Maquieira A (2000). Coconut coir waste, a new and viable ecologically-friendly peat substitute. Acta. Hortic. 517:279-286.

OECD (1984). Guideline for testing of chemicals No 207. Earthworm Acute Toxicity Test Organization for Economic Co-Operation and Development. Paris. France.

OECD (2004a). Guideline for testing of chemicals No 222. Earthworm Reproduction Test (Eisenia fetida/andreI). Organization for Economic Co-Operation and Development, Paris, France.

P Mangala CS De Silva, Cornelis AM, Van Gestel (2009). Development of an alternative artificial soil for earth worm toxicity testing in tropical countries. Appl. Soil Ecol. 43:170-174.
Puurtinen HM, Martikainen EAT (1997). Effect of Soil Moisture on Pesticide Toxicity to an Enchytraeid Worm, Enchytraeus sp. Earth Environ. Sci. 33(1):34-41.

Robertson A (1993). Peat, horticulture and environment. Biodiversity Conservation. 2:541- 47.

Römbke J, Garcia MV, Scheffczyk A, ECT Oekotoxikologi (2007). Arch Environ Contam Toxicol. Effects of the fungicide benomyl on earthworms in laboratory tests under tropical and temperate conditions. 53(4):590-8.

Sian R, Ellisa Mark E, Hodsona Philip Wegeb (2007). Eur. J. Soil Biol. 43(1):S239-S245.

Sundaram TK, Natrajan A, Chandrasekaran D, Mani K (2001). Determination of soil properties. Centre of advanced studies in Poultry science \& Animal feed analytical and quality control laboratory Veterinary college and research institute, Namakkal Tamil Nadu Veterinary and Animal Science University.

TOXSTAT version 3.5, (2003). Western Ecosystems Technology Inc., Central Avenue; WY 82001.

Van soest PJ, Robertson JB, Lewis BS (1975). Department of Animal Science and Division of Nutritional Sciences, Itaca, NY. 